\title{
Atrial fibrillation and other cardiovascular diseases as risk factors for stroke
}

\section{Alma Sijamija*, Mustafa Strukar, Alma Agačević, Lejla Granov}

Travnik General Hospital, Travnik, Bosnia and Herzegovina

RECEIVED:

September 21, 2014
KEYWORDS: stroke, atrial fibrillation, risk factors.

CITATION: Cardiol Croat. 2014;9(9-10):366.

*ADDRESS FOR CORRESPONDENCE: J. U. Bolnica Travnik, Kalibunar bb, 72270 Travnik, Bosnia and Herzegovina. Phone: +387-61780085 / E-mail: alma.sijamija@hotmail.com

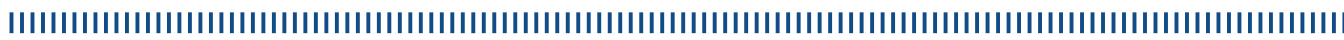

INTRODUCTION: Cerebrovascular insult is defined as the loss of brain function due to a disturbance in the blood supply to the brain. This disturbance is due to either ischaemia or hemorrhage. Risk factors for stroke include old age, hypertension, previous stroke, diabetes, high cholesterol, tobacco smoking and atrial fibrillation (AF). Hypertension is the most important modifiable risk factor of stroke. About $87 \%$ of strokes are ischemic, the rest are hemorrhagic.

GOAL: The aim of this study is to determinate the frequency of AF and other cardiovascular diseases (CVD) in patients with stroke.

PATIENTS AND METHODS: We retrospectively evaluated the histories of patients admitted to Neurology Department in Travnik Hospital with acute stroke during the one-year period (May 2013-May 2014). In each patient a neurological examination was performed, with CT of the brain to confirm stroke and cardiology examination.

RESULTS: A total of 451 patients (mean age $70.15 \pm 9.996$ years)with confirmed stroke or TIA were treated. Out of these $83.6 \%$ of patients were with ischemic stroke $12.9 \%$ with hemorrhagic and $3.5 \%$ patients with ihemorrhagic transformationi. There were $49.4 \%$ male and $50.6 \%$ female patients. The most common risk factor was hypertension, found in $82 \%$ of patients. Diabetes mellitus was noted in $33.7 \%$ patients, AF in $21.5 \%$ patients. $23.1 \%$ had the previous history of ischaemic heart disease and other CVD. Among all patients, $23.3 \%$ died within 7 days of the onset of the symptoms. In the group of the patients with AF the mortality rate was significantly higher (45.4\%) then in the group without $\mathrm{AF}(17.2 \%)(\mathrm{p}<0.0001)$.

CONCLUSION: Heart rhythm disturbances, AF increase the risk of onset and recurrence of embolic stroke. Timely detection of cardiac arrhythmias as well as hypertension and other risk factors and their appropriate treatment can help to prevent the onset of stroke and thus significantly reduce the number of disabled persons and the cost of treatment making the life in the third age better.

2. Ay H, Furie KL, Singhal A, Smith WS, Sorensen AG, Koroshetz WJ. An evidence-based causative classification system for acute ischemic stroke. Ann Neurol. 2005;58(5):688-97.

3. Halkes PH, van Gijn J, Kappelle LJ, Koudstaal PJ, Algra A. Medium intensity oral anticoagulants versus aspirin after cerebral ischaemia of arterial origin (ESPRIT): a randomised controlled trial. Lancet Neurol. 2007;6(2):115-24. 